\title{
Brazilian Study of Nutrition and Health (EBANS) - Brazilian data of ELANS: methodological opportunities and challenges
}

\author{
(D) Mauro Fisberg ${ }^{1}$ \\ (D) Irina Kovalskys ${ }^{2}$ \\ Aqatha Nogueira Previdelli ${ }^{3}$ \\ (iD) loná Zalcman Zimberg ${ }^{4}$ \\ (D) Ana Paula Wolf Tasca Del'Arco \\ (iD) Gerson Luis de Moraes Ferrari
}

\begin{abstract}
1. Pensi Institute - Foundation José Luiz Egydio Setúbal - Sabará Children's Hospital, São Paulo, SP, Brasil and Department of Pediatrics, Unifesp - Federal University of São Paulo, São Paulo, SP, Brasil 2. International Life Science Institute (ILSI-Argentina) - Committee of Nutrition and Faculty of Medical Sciences University Favaloro, Buenos Aires, Argentina 3. Faculty of Biological Sciences and Health - University São Judas Tadeu, São Paulo, Brasil 4. Department of Psychobiology - Unifesp, São Paulo, Brasil 5. Department of Pediatrics, Unifesp - Federal University of São Paulo, São Paulo, SP, Brasil 6. Centro de Investigación en Fisiologia del Ejercicio - CIFE, Universidad Mayor, Santiago, Chile and Department of Pediatrics, Unifesp - Federal University of São Paulo, São Paulo, SP, Brasil
\end{abstract}

http://dx.doi.org/10.1590/1806-9282.65.5.669

\section{SUMMARY}

BACKGROUND: Epidemiological studies with dietary variables are complex methodologically, being the researcher responsible for anticipating, controlling, reducing and preventing methodological errors. Obesity accounts for almost one-third of the world's population and has consequences for childhood and adolescence. Multifactorial disorder must be faced in several aspects, being food and physical activity, modifiable risk factors. The EBANS aims to perform a diagnosis of the nutritional status of the Brazilian population from 15 to 65 years old, from all regions, and the parameters associated with obesity, with several possibilities of correlating data.

METHODOLOGICAL PROCESS: Part of the ELANS study $(n=9218)$, the EBANS $(n=2000)$ has a weighted sample and data collection that allows: to evaluate the socioeconomic level of the population; perform a diagnosis of nutritional status (through anthropometric variables); to evaluate food intake (R24h and FFQ for beverages); and evaluate physical activity practice (IPAQ-long and accelerometer).

METHODOLOGICAL OPPORTUNITIES: With national coverage, EBANS has the potential to compose regional analyzes, portray the current nutritional epidemiological condition, food consumption and physical activity pattern of the Brazilian population, at different life stages, and may have their data analyzed together or stratified, offering useful subsidies for the formulation of public policies.

METHODOLOGICAL CHALLENGES: Each methodological step was designed to reduce errors and biases related to methodological challenges.

CAAE REGISTRATION: 31670314.8.0000.5567.

FINAL CONSIDERATIONS: Of great potential for future data analysis, EBANS tries to contribute to the generation of knowledge to foment policies and actions capable of changing the current obesity scenario.

KEYWORDS: Cross-sectional studies. Obesity. Food Consumption. Exercise. Anthropometry.

DATE OF SUBMISSION: 29-Aug-2018

DATE OF ACCEPTANCE: 01-Sep-2018

CORRESPONDING AUTHOR: Ana Del Arco

Rua Botucatu, 598, São Paulo, Brasil - 04023-062

E-mail: apwt.delarco@gmail.com 


\section{INTRODUCTION}

Epidemiological studies in health are quite complex in its methodological design, especially those that involve dietary variables when the data collection instrument are questionnaires or similar protocols, which can cause omission and/or sub-reporting of data ${ }^{1-3}$. After identifying the main sources of error in their study, researchers should anticipate them and be able to propose methodologies that can control, reduce, and even prevent these errors ${ }^{4}$. Scientific and methodological rigor, as well as the application of additional methodologies in order to reduce random and systematic errors, are vital and characterize a methodological differential in epidemiological research ${ }^{5}$.

Population studies with the same methodological protocol covering the various stages of life have a high application cost and, consequently, are scarce. The Household Budget Survey (Pesquisa de Orçamentos Familiares POF) aims to map the pattern of consumption, and thus, the expenses of the Brazilian population and is used by researchers as a source of data to identify the pattern of food consumption by Brazilians, which has been undergoing changes over time $^{6}$.

Currently, obesity is a public health problem worldwide, classified as an epidemic by the World Health Organization (WHO) and representing almost one-third of the world population ${ }^{7}$. The condition of overweight in the context of public health is determined by several factors, involving from genetic to environmental factors that permeate the lifestyle of the individual. The causes and factors associated with obesity denote that obesity is a multifactorial disorder $^{8-10}$. Nutrition and physical activity are factors that have an important role in the context of obesity and are modifiable risk factors, meaning they may be altered by individual ${ }^{8.11}$.

One of the main goals of epidemiological studies on health is producing knowledge and identifying variables related to a determined outcome in order to subsequently act on the variables to change the outcome, avoiding the worsening of a certain health condition $^{12}$. The Brazilian Study of Nutrition and Health (EBANS) proposes an updated diagnosis of the nutritional status of the Brazilian population, as well as of the parameters associated with obesity, such as food consumption and practice of physical activity, with various possibilities of correlation between these data, which brings scientific subsidies related to the diagnosis of the problem so that the fight against the obesity epidemic can be effective.

\section{METHODS}

The EBANS is a descriptive, cross-sectional, population-based study part of the Latin American Study of Nutrition and Health/Estudio Latinoamericano de Nutrición y Salud (ELANS), which was conducted in eight countries in Latin America (Argentina, Brazil, Chile, Colombia, Costa Rica, Ecuador, Peru, and Venezuela) ${ }^{13}$.

All participants signed an Informed Consent Form and/or a Assent Form (for adolescents), and the study is registered in the CAAE under the number: 31670314.8.0000.5567.

\section{Sample size definition and study population}

A study of national scope, representative of the Brazilian urban population of all five macro-regions of the country, the EBANS included individuals from 15 to 65 years old, of all socioeconomic levels.

We used systematic random sampling for selecting the cities included. The urban conglomerates were selected in a systematic way, and smaller cities were randomly selected based on their population density. Within the conglomerates, the Primary Sampling Units (PSU), represented by municipalities, districts, and residential areas, were randomly selected, as were the Secondary Sampling Units (SSU), defined as the census sectors. For the selection of the PSUs, we used the probability proportional to size (PPS), with a simple random sampling of the sample size to ensure the principle of statistical independence. Within each PSU allocated in the sample, a sampling point was randomly selected by means using PPS: the SSUs, which were defined based on the cartographic division of the census sectors ${ }^{14}$. In each SSU, the selection of the households was carried out in systematically, with each residential block traveled clockwise by the interviewer, with a sampling interval of three households. Within the households, the selection of individuals was controlled by quotas, always respecting the criteria of selection of half of the individuals with the closest birthday and the other half with the most distant birthday from the date of the interview.

The sample size and level of error calculations of EBANS (confidence level of 95\%) adhered to gen- 
eral criteria with the guarantee of a minimum basis of cases for disaggregation of data according to the variables of interest. We calculated the number of probable cases to the lowest socioeconomic level, the lowest age range, and for each gender, all obtained from the initial sample universe of 2,109 individuals (Table 1).

The final EBANS sample had 2,000 individuals (Figure 1), and the population of EBANS was characterized as described in Table 1.

\section{Protocol for data collection}

Following a standardized ELANS protoco ${ }^{13}$, the data collected proposed to (1) diagnose the nutritional status (data measured using anthropometry), (2) evaluate the food consumption and (3) evaluate the practice of physical activity and energy expenditure of the Brazilian population.

The data were collected between October 2014 and July 2015, by means of two visits, respecting an eight-day interval and ensuring at least the collection of one weekend day, as outlined in Figure 2.

\section{Instruments for data collection}

Anthropometry

The anthropometric data were measured using standardized procedures in the literature ${ }^{15}$, always

FIGURE 1. DIAGRAM OF EBANS PARTICIPANTS

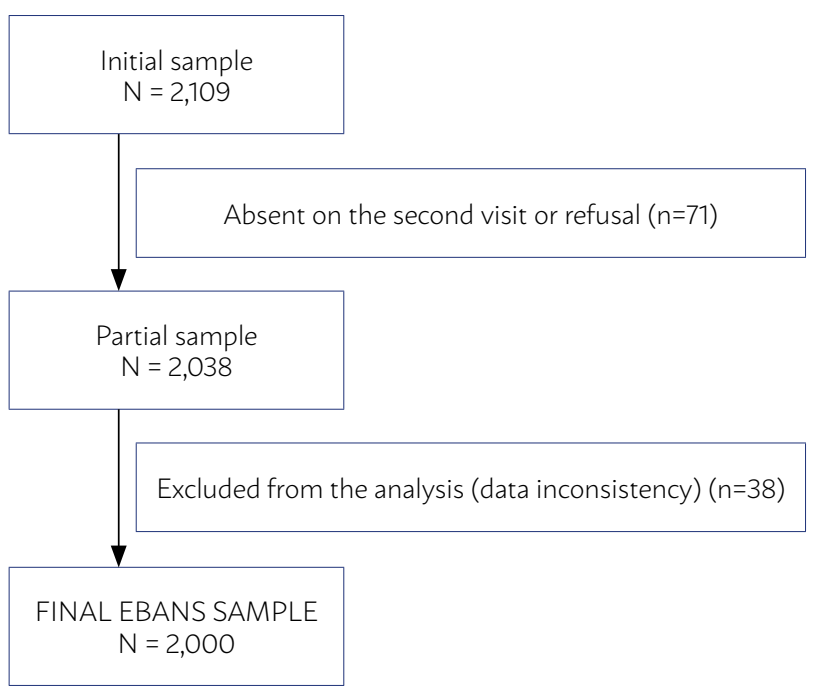

in duplicate, and whenever there was a difference greater than 0.5 centimeters $(\mathrm{cm})$ or 0.5 kilograms $(\mathrm{kg})$ between them, a third measurement was performed. The measurements were recorded on a form and the data analyzed was the average of the measurements obtained.

The field interviewers, responsible for performing the anthropometric measures, were trained and supervised by anthropometrists in order to ensure better precision and accuracy of the data. Some unforeseen events were anticipated and the interviewers were instructed to make a clarifying note in the form if the individual refused to remove any items of clothing or heavy objects, if they were wearing heavy items of clothing (like jeans), if they refused or were unable to step on the scale or be correctly positioned to have their height measured, or had a hairstyle that could also interfere with the accuracy of the measurement of the neck circumference, if there was a refusal to lift their top for the measurement of waist circumference, and the impossibility of measuring the circumference beyond the maximum extension of the measuring tape and of using the scale to measure weight exceeding $200 \mathrm{~kg}$ (in this case, the declared weight was considered).

The measurement of body weight in $\mathrm{kg}$ was done with the aid of Sanny ${ }^{\circledR}$ portable scale with a maximum capacity of $200 \mathrm{~kg}$ and an accuracy of $0.1 \mathrm{~kg}$, which was placed next to a wall and on a flat surface. The participants were instructed to remove shoes and socks, heavy items of clothing and accessories and objects from their pockets. After stabilizing the scale (with the measurement indicating zero), the participants stepped on the scale and stood still until the weight on the dashboard was fully stabilized.

The height was measured in $\mathrm{cm}$ and in whole numbers (rounded down when the measurement was less than $0.5 \mathrm{~cm}$ and rounded up when exceeding $0.5 \mathrm{~cm}$ ) with the aid of a portable Sanny ${ }^{\circledR}$ stadiometer with an accuracy of $0.1 \mathrm{~cm}$ and a maximum of $205 \mathrm{~cm}$, which was placed on a flat surface, against a smooth wall without skirting. The participants, barefoot, were positioned with their backs straight,

TABLE 1. CHARACTERIZATION AND DISTRIBUTION OF THE EBANS SAMPLE

\begin{tabular}{|c|c|c|c|c|c|c|c|c|c|c|}
\hline & \multicolumn{3}{|l|}{ SEL * } & \multicolumn{4}{|l|}{ Age strata } & \multicolumn{2}{|l|}{ Gender } & \multirow[t]{2}{*}{ Error } \\
\hline & High & Medium & Low & 15-19.9 & $20-34.9$ & $35-49.9$ & $50-65.9$ & Female & Male & \\
\hline$N(\%)$ & $169(8.4)$ & $915(45.8)$ & $916(45.8)$ & $235(11.8)$ & 745 (37.2) & $608(30.4)$ & $412(20.6)$ & 1,058 (52.9) & $942(47.1)$ & $2.79 \%$ \\
\hline
\end{tabular}

*SEL (socioeconomic level): Critério Padrão de Classificação Econômica Brasil40; classified as High (A1, A2, B1 class), Medium (B2, C1 class), and Low (C2, D, E class). 
feet together, knees stretched, in the Frankfurt plane (with their head, back, buttocks and heels touching the wall; or with the greatest number of body parts as possible touching the wall). At the time of measurement, participants were instructed to breathe in for the correct measurement of height, and the interviewer was positioned in front of the stadiometer, using a platform to facilitate the reading.

After taking the anthropometric measurements, the average of the measurements obtained was used for calculating the Body Mass Index (BMI) $\left(\mathrm{kg} / \mathrm{m}^{2}\right)$, according to the equation:

$$
\frac{\text { Weight (kilograms) }}{\text { Height }^{2} \text { (meters) }}
$$

The nutritional status was classified using the BMI calculated according to the parameters established by the WHO for individuals older than 19 years ${ }^{16}$ and, for adolescents from 15 to 19 years old, we used the parameters of BMI per gender and age ${ }^{17}$.

The measurement of the neck circumference is an anthropometric parameter that has been used and described in the literature for measuring nutritional status, especially as a marker of visceral adiposity and insulin resistance ${ }^{18.19}$. Its measurement is less embarrassing, faster and easier for the interviewers. The neck circumference was measured in $\mathrm{cm}$ with the aid of an inelastic Sanny ${ }^{\circledR}$ tape with a precision of $0.1 \mathrm{~cm}$ and a maximum length of $200 \mathrm{~cm}$. The tape was positioned horizontally, perpendicular to the axis of the neck, over the thyroid cartilage (point below the larynx) while the individual was in an erect position, looking forward and with their shoulders relaxed $^{20}$.

The measurements of waist and hip circumference were also taken in $\mathrm{cm}$ using the same instrument, following the parameters recommended by the $\mathrm{WHO}^{16.20}$. To measure the waist circumference, the midpoint between the iliac crest and the last rib was located with the interviewer positioned next to the individuals and instructing them to relax their abdomen, outstretch their arms, keep their feet parallel, breath in and hold their breath for a few seconds until the interviewer found the exact point to take the measurement (mid-point of the distance obtained between the iliac crest and the last rib). To measure the hip circumference, the participant was instructed to wear light clothing (for better accuracy), stand upright with their abdomen relaxed, arms at the side of the body, feet together, body weight distributed evenly between both legs - the measurement was

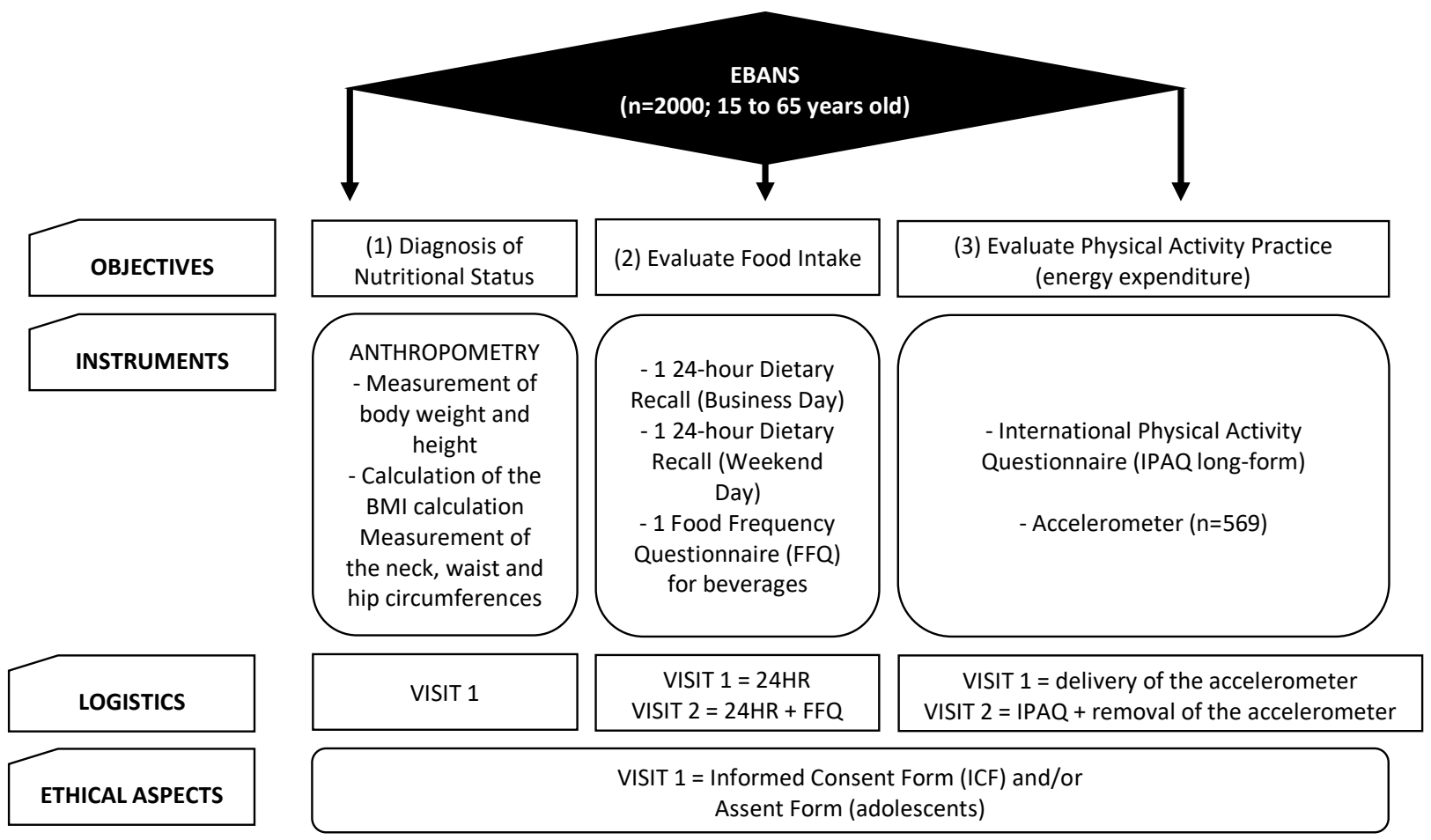


obtained at the point of the greatest circumference on the gluteal region.

\section{Food intake}

The data of food intake characterize a very important methodological step in epidemiological studies, since the instrument and the methodology adopted may determine the scientific quality of the data and, consequently, of the entire research. In EBANS, food intake data were collected using two instruments established in the literature: the 24-hour Dietary Recall survey (24HR), which ensures better adhesion of the interviewee since it is faster and requires less memory time of the respondents ${ }^{3.21}$; and the Food Frequency Questionnaire (FFQ) (for beverages), which is widely used in studies with large sample size since it is of easy application, low cost, and the information generated is easy to processing for entry using software ${ }^{22}$.

Both instruments are based on the self-reporting of the interviewees, so there may be a methodological bias of underreported data ${ }^{1.2}$. However, additional techniques and methodologies were implemented to reduce possible biases and errors related to the variability of the observer, the instrument, and the subject interviewed ${ }^{5}$.

The first step was to ensure that the field staff was properly trained for the filling out of the instruments, thus controlling the bias and the intra- and interpersonal variability, minimizing the possible errors assigned to the observer. They were trained with meticulous detailing of the 24HR manual, with constant monitoring of field work by a nutritionist in charge for the immediate detection and correction of possible errors in data collection and the random selection of data for insertion in duplicate.

The 24HR is a tool capable of providing detailed information about the dietary consumption of the previous day or the last 24 hours and, if replicated, can estimate the habitual consumption of the individual. To ensure greater scientific reliability of the data from the $24 \mathrm{HR}$ and reduce possible errors related to this instrument, the $24 \mathrm{HR}$ was applied in person in two visits, for all participants, ensuring that one 24HR represented a business day and the other a weekend day, thus ensuring the representativeness of all days of the week, randomly distributed. With the purpose of improving the accuracy of the data, we used an auxiliary photo album containing pictures of the sizes of portions and utensils used as homemade measure ${ }^{22}$. Complementary to the data obtained from the $24 \mathrm{HR}$, we used a qualitative FFQ adapted only to investigate the frequency of consumption of beverages ingested (number of times per day/week/month), including alcoholic and non-alcoholic beverages ${ }^{23}$.

The subject interviewed represents another source of error in research protocols that do not use direct methods of food intake (such as rest-intake), being necessary to use additional techniques to reduce possible errors linked to the subject interviewed, who may sub-report data due to embarrassment or forgetfulness ${ }^{1.2}$. We used the Multiple Pass Method (MPM), an additional methodology developed by the United States Department of Agriculture (USDA), to assist the respondent in the detailing of his food-intake report, divided into five steps: quick listing, listing of food items usually forgotten, definition of meals and their time, detailing cycle, and final review ${ }^{24}$.

After the data collection, another step that requires methodological care is the transfer of data for the analysis by software. After the analysis of data consistency, a team of trained nutritionists converted the quantities reported in household measures into values in grams (g) and milliliters (ml) and inserting them into the Nutrition Data System for Research software (NDS version 2013-R University of Minnesota, MN, USA) $)^{25}$ for the dietary calculation. Since the NDS-R is an American software, some food items relating to Brazilians culture and habits standardized, according to Kovalskys et al. ${ }^{26}$.

A software for statistical modeling using the Multiple Source Method (MSM), available at $<$ https://msm.dife.de/tps/en>, was used for estimating the usual intake, being capable of estimating the usual intake of nutrients, foods and food groups, eliminating intrapersonal variance of consumption, allowing for the estimation of usual intake in both population and individual levels ${ }^{27.28}$. This method requires that you have a repetition of the consumption data (such as the $24 \mathrm{HR}$ ) in a random subsample of the population to provide estimates of usual intake. It is noteworthy that for the EBANS the replication was made in $100 \%$ of the population, and, therefore, the data of the $24 \mathrm{HR}$ were used in a quantitative model that is applied to estimate the quantity consumed by means of linear regression. And in a second model, a probability one, which is estimated by logistic regression with random effects, we assumed the probability 
of consumption of $100 \%$ (i.e., 1), because it is the consumption of nutrients and energy ${ }^{27.28}$.

\section{Physical activity}

The collection of data of physical activity represents another methodological step that determines the scientific quality of the results if the instrument used is not properly applied, given that physical activity can occur in different contexts and the individual may not report it because they do not believe something is characterized as physical activity $^{29}$. In this scenario, it is crucial that the instrument and the interviewer guide the reasoning and the reflection of the interviewee to describe all activities, whether in leisure, transportation, work and also in guided sports practices. Initially proposed by the WHO, the International Physical Activity Questionnaire (IPAQ long form) is an instrument validated both internationally and nationally ${ }^{30}$ and is reliable to measure the energy expenditure of individuals, in particular, those that reside in urban areas. However, it is a subjective measure, since it depends on the interviewee's self-reporting and they usually overestimate the report. Therefore, it is prudent to use direct methods as complements for the higher scientific quality of the data ${ }^{29}$.

In addition to the application of the long-form IPAQ, in order to obtain better accuracy of information, in 30\% EBANS sample, the level of physical activity was also determined using an accelerometer, which provides a direct and objective measurement. The accelerometer is an instrument that has been used in the laboratory and in real life conditions to measure objectively the level of physical activity ${ }^{31}$, mainly for adults. It provides a reliable measure with good validity ${ }^{32}$; however, there are some limitations that may underestimate the result, for example, not being able to measure isometric strength activities and aquatic activities, in addition to its high cost of application, which has limited its use in large epidemiological studies ${ }^{29}$.

Always in search of better data precision and accuracy, the field team was trained in completing the longform IPAQ in its version adapted by Mexican research$\mathrm{ers}^{33}$, aiming to collect information about the routine practice of physical activity among participants, using as a reference the week before the interview. The field team was monitored by researchers in charge of detecting and correcting possible errors. After the data collection, a score for physical activity was standard- ized multiplying weekly frequency (days/week) by the average time of activity (minutes/day), for each of the domains of physical activity presented in the questionnaire (leisure and transportation), and for each type of physical activity (walking, moderate activity and vigorous activity). For each domain, a score of physical activity was obtained (minutes/week). Data were analyzed in accordance with the IPAQ scoring protocol, available at <https://sites.google.com/site/theipaq/scoring-protocol>. IPAQ data are reported as minutes per day of sitting, moderate activity (including walking) and vigorous activity and as MET-minutes of MVPA (minutes of walking x3.3 METS+minutes of moderate activity (excluding walking) $\mathrm{x} 4.0$ METS+minutes of vigorous activity x8.0 METS).

Regarding the direct measurement of the level of physical activity, the accelerometers GT3X (ActiGraph, Pensacola, FL) were delivered in the first home visit and the interviewer explained how to use the instrument, always instructing the respondent to attach the accelerometer at the waist using an elastic band over the midaxillary line on the right side of the body, using the instrument at all times while awake, removing it only for bathing or performing aquatic activities. After seven days of continuous use, coinciding with the second home visit, the instrument was collected and then the integrity of the data was verified by the team in charge using the ActiLife software version 6 (ActiGraph, Pensacola, FL).

\section{DISCUSSION}

\section{Methodological Opportunities}

The EBANS is a survey of national coverage, and its data were obtained from the protocol standardized by ELANS, thus generating a scientific opportunity of direct comparison between the data from research in Latin American participants of the ELANS and allowing for a reflection on a set of information concerning the fight against chronic non-communicable diseases and obesity and originated from different countries, but with similar conditions of being low- and middle-income places ${ }^{34}$. The EBANS data, which compose the ELANS database, can be useful and strategic for the formulation of public policies in the context of the Pan-American Health Organization (PAHO), with a focus on Latin America.

In addition to this broader approach, through analysis at a regional level, the data of the present 
study depict the current nutritional epidemiological conditions of food consumption and physical activity pattern of the Brazilian population aged from 15 to 65 years. This allows us to determine the prevalence of excess weight, nutritional inadequacies, and sedentary lifestyle and the implications of the variants that interfere directly on these. The understanding of the size and relevance of this problem in the population is vital so that effective action can be implemented. In Brazil, obesity has grown 60\% over the past ten years, the indices of excess weight are increasing over time, and currently, more than half of the Brazilian population presents excess weight $^{6.35}$. The Ministry of Health has the goal to stabilize the prevalence of obesity and contain its growth in the adult population until 2019 by means of intersectoral health policies that cover food and nutritional security ${ }^{36}$.

It is widely known that obesity is a multifactorial disorder ${ }^{8-10}$ and that lifestyle encompasses factors that can be modified, resulting in significant improvements in various parameters of health and nutritional status ${ }^{1}$. Food consumption and physical activity pattern, therefore, are variables that can be modified by the individual as a result of well-targeted public policies. The EBANS brings data on food consumption and physical activity that can be analyzed together or stratified, generating various methodological opportunities.

Determining the practice of physical activity in a population, to identify individuals who are active or insufficiently active, as well as the implications that lead them to have certain behavior, can give subsidies are useful for formulating public policies capable of changing the backdrop of insufficient practice of physical activity, which seems to be the reality of a large part of the Brazilian population ${ }^{35.36}$. The great methodological differential of EBANS is the possibility of confronting the subjective indicators of physical activity with direct data (obtained using the accelerometer).

Table 2 summarizes the main methodological opportunities of data analyses generated on EBANS and the main methodological challenges linked to the study.

\section{Methodological challenges}

During the design of EBANS, when defining the study population and the representativeness desired, we initially intended to include children and adolescents under the age of 15 years. However, this
TABLE 2. METHODOLOGICAL OPPORTUNITIES AND CHALLENGES OF EBANS
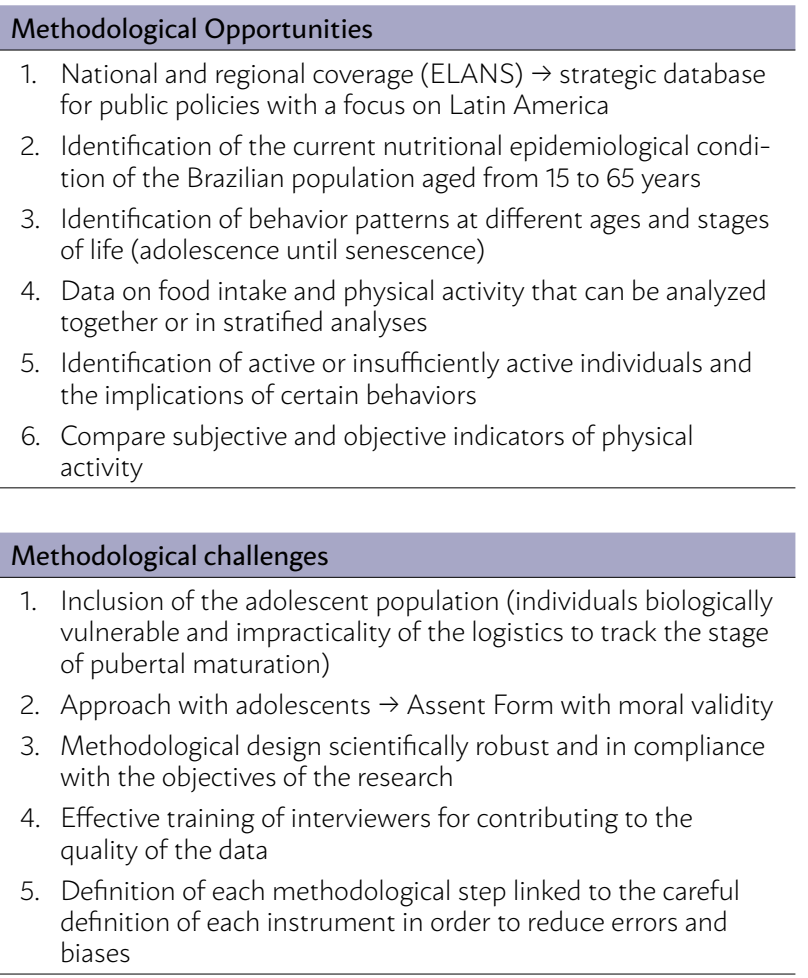

intention was characterized as a methodological challenge, given that these populations are biologically vulnerable and, in case of adolescents younger than 15 years old, it would be necessary to check the stage of pubertal maturation ${ }^{37}$. In studies with adolescent population younger than 15 years old, this step is crucial, because, depending on the pubertal stage, the body composition may not faithfully reflect the nutritional status, since this stage of life causes considerable physiological and biological changes in the body ${ }^{38}$. We have chosen to consider 15 years old as the minimum age for inclusion in the study since by then puberty has usually already reached its peak ${ }^{38}$. Another challenging aspect in relation to adolescents was how to approach them since they should understand the purpose of the research and agree to participate through the Assent Form, which needs to be developed and applied in accordance with certain criteria in order to have moral validity ${ }^{39}$.

After the challenge of a methodological design that was scientifically robust, the first practical challenge of EBANS was to train the interviewers, since the good relationship between the interviewers and participants could affect the quality of the data, es- 
pecially when the research is related to obesity, food consumption, and practice of physical activity, themes that have an emotional impact on individuals due to its various associated aspects.

The data collection instruments elected for each stage of the research were widely discussed by the EBANS team, and each methodological step linked to each instrument was designed from the perspective of reducing errors and biases in connection to the methodological challenges faced, as already explained throughout the article, in the methodological description of the study.

\section{FINAL CONSIDERATIONS}

The EBANS is a study with great potential for future data analyses, which can provide various stratified descriptive results and also correlations between variables. Scientifically, it brings many opportunities to aggregate and contributes to the generation of data that may promote policies and effective actions to society. The production of knowledge, as well as the access and the understanding of the population to the information generated about issues that directly affect their lives is essential so that they can make choices and be agents of change of their own habits.

\section{RESUMO}

INTRODUÇão: Estudos epidemiológicos com variáveis dietéticas são complexos metodologicamente, e o pesquisador é responsável por antecipar, controlar, reduzir e prevenir erros metodológicos. A obesidade representa quase 1/3 da população mundial e agrega consequências que são observadas na infância e na adolescência. Desordem multifatorial deve ser enfrentada sob diversos aspectos, sendo alimentação e atividade física fatores de risco modificáveis. O EBANS se propõe a realizar um diagnóstico do estado nutricional da população brasileira de 15 a 65 anos, de todas as regiões, e dos parâmetros associados à obesidade, com diversas possibilidades de correlacionar dados.

PROCESSO METODOLÓGICO: Parte do estudo ELANS (n=9218), o EBANS (n=2000) tem amostra ponderada e coleta de dados que permite: avaliar o nível socioeconômico da população; realizar diagnóstico do estado nutricional (por meio de variáveis antropométricas); avaliar consumo alimentar (R24h e QFA para bebidas); e avaliar prática de atividade física (IPAQ-longo e acelerômetro).

OPORTUNIDADES METODOLÓGICAS: De abrangência nacional, o EBANS tem potencial para compor análises regionais, retratar a atual condição epidemiológica nutricional, de consumo alimentar e padrão de atividade física da população brasileira, em diferentes estágios da vida, podendo ter seus dados analisados em conjunto ou estratificados, oferecendo subsídios úteis para a formulação de políticas públicas.

DESAFIOS METODOLóGicos: Cada etapa metodológica foi desenhada a fim de reduzir os erros e vieses atrelados aos desafios metodológicos.

REGISTRO CAAE: 31670374.8 .0000 .5567$.

CONSIDERAÇÕES FINAIS: De grande potencial para futuras análises de dados, o EBANS intenta contribuir na geração de conhecimento para fomentar políticas e ações capazes de alterar o atual cenário de obesidade.

PALAVRAS-Chave: Estudos transversais. Obesidade. Consumo de alimentos. Exercício. Antropometria.

\section{REFERENCES}

1. Rodrigues PRM, Souza RAG, De Cnop ML, Monteiro LS, Coura CP, Brito $A P$, et al. Dietary quality varies according to data collection instrument: a comparison between a food frequency questionnaire and 24-hour recall. Cad Saúde Pública. 2016;32(2):e00047215.

2. Avelino GF, Previdelli AN, Castro MA, Marchioni DML, Fisberg RM. Sub-relato da ingestão energética e fatores associados em estudo de base populacional. Cad Saúde Pública. 2014;30(3):663-8.

3. Fisberg RM, Slater B, Marchioni DML, Martini LA. Inquéritos alimentares: métodos e bases científicos. São Paulo: Editora Manole; 2005.

4. Margetts BM, Nelson M. Design concepts in nutritional epidemiology. New York: Oxford University Press; 1991.

5. Hulley SB, Cummings SR, Browner WS, Grady DG, Newman TB. Delineando a pesquisa clínica. $4^{\mathrm{a}}$ ed. Porto Alegre: Artmed; 2015.

6. Instituto Brasileiro de Geografia e Estatística (IBGE). Pesquisa de Orçamentos Familiares (POF). 2008-2009. Antropometria e estado nutricional de crianças, adolescentes e adultos no Brasil. [cited 2018 May 16]. Available from: https://biblioteca.ibge.gov.br/visualizacao/livros/liv45419. pdf

7. Ng M, Fleming T, Robison M, Thomson B, Graetz N, Margono C, et al. Global, regional, and national prevalence of overweight and obesity in children and adults during 1980-2013: a systematic analysis for the Global Burden of Disease Study 2013. Lancet. 2014;384(9945):766-81.
8. Craigie AM, Lake AA, Kelly SA, Adamson A|, Mathers IC. Tracking of obesity-related behaviors from childhood to adulthood: a systematic review. Maturitas. 2011;70(3):266-84.

9. Dâmaso A, Guerra RL, Botero JP, Prado WL. Etiologia da obesidade. In: Dâmaso A, ed. Obesidade. São Paulo: Medsi; 2003. p.3-6.

10. Stunkard AJ. Factores determinantes de la obesidad: opinión actual. Washington: Organização Panamericana da Saúde; 2000.

11. Azevedo MR, Araújo CL, Silva MC, Hallal PC. Tracking of physical activity from adolescence to adulthood: a population-based study. Rev Saúde Pública. 2007;41(1):69-75.

12. Borges TT, Rombaldi AJ, Knuth AG, Hallal PC. Knowledge on risk factors for chronic diseases: a population-based study. Cad Saúde Pública. 2009;25(7):1511-20.

13. Fisberg M, Kovalskys I, Gómez G, Rigotti A, Cortés LY, Herrera-Cuenca M, et al; ELANS Study Group. Latin America Study of Nutrition and Health (ELANS): rationale and study design. BMC Public Health. 2016;16:93.

14. Instituto Brasileiro de Geografia e Estatística (IBGE). 2010. Censo 2010. [cited 2018 May 16]. Available from: http://censo2010.ibge.gov.br/.

15. Stewart A, Marfell-Jones M, Olds T, Ridder H. International standards for anthropometric assessment. Lower Hutt: ISAK; 2011. 
16. World Health Organization. Obesity: preventing and managing the global epidemic: Report of a WHO consultation. World Health Organ Tech Rep Ser. 2000;894:i-xii, 1-253.

17. Onis M, Onyango AW, Borghi E, Siyam A, Nishida C, Siekmann l, et al. Development of a WHO growth reference for school-aged children and adolescents. Bull World Health Organ. 2007;85(9):660-7.

18. Stabe C, Vasques AC, Lima MM, Tambascia MA, Pareja JC, Yamanaka A, et al. Neck circumference as a simple tool for identifying the metabolic syndrome and insulin resistance: results from the Brazilian Metabolic Syndrome Study. Clin Endocrinol (Oxf). 2013;78(6):874-81.

19. Preis SR, Massaro JM, Hoffmann U, D'Agostino RB Sr, Levy D, Robins SJ, et al. Neck circumference as a novel measure of cardiovascular risk: the Framingham Heart study. J Clin Endocrinol Metab. 2010;95(8):3701-10.

20. World Health Organization (WHO). Measuring obesity: classification and distribution of anthropometric data. and description of anthropometric data : report on a WHO consultation on the epidemiology of obesity, Warsaw, 21-23 October 1987. Copenhagen: World Health Organization, Regional Office for Europe;1989.

21. Willett W. Nutritional epidemiology. $3^{\text {rd }}$ ed. New York: Oxford University Press; 2012.

22. Levy-Costa RB, Sichieri R, Pontes NS, Monteiro CA. Household food availability in Brazil: distribution and trends (1974-2003). Rev Saúde Pública. 2005;39(4):530-40

23. Kovalskys I, Indart Rougier P, Amigo MP, De Gregorio MJ, Rausch Herscovici C, Karner M. Food intake and anthropometric evaluation in schoolaged children of Buenos Aires. Arch Argent Pediatr. 2013;111(1):9-14.

24. Moshfegh AI, Rhodes DG, Baer DI, Murayi T, Clemens IC, Rumpler WV, et al. The US Department of Agriculture Automated Multiple-Pass Method reduces bias in the collection of energy intakes. Am | Clin Nutr. 2008;88(2):324-32.

25. Nutrition Coordinating Center (NCC). Nutrition Data System For Research - NDS-R. Features. [cited 2018 May 16]. Available from: http:// www.ncc.umn.edu/products/features/

26. Kovalskys I, Fisberg M, Gómez G, Rigotti A, Cortés LY, Yépez MC, et al; ELANS Study Group. Standardization of the food composition database used in the Latin American nutrition and health study (ELANS). Nutrients. 2015;7(9):7914-24

27. Harttig U, Haubrock J, Knüppel S, Boeing H; EFCOVAL Consortium. The MSM program: the web-based statistics package for estimating usual dietary intake using the Multiple Source Method. Eur J Clin Nutr. 2011;65(Suppl 1):S87-91.

28. Haubrock J, Nöthlings U, Volatier JL, Dekkers A, Ocké M, Harttig U, et al. Estimating usual food intake distributions by using the multiple source method in the EPIC-Potsdam Calibration Study. J Nutr. 2011;141(5):91420.

29. Cafruni $C B$, Valadão RCD, Mello ED. How to assess physical activity? Rev Bras Cien Saúde. 2012;10(33):61-71.

30. Pardini R, Matsudo S, Araújo T, Matsudo V, Andrade E, Braggion G, et al. Validação do questionário internacional de nível de atividade física (IPAQ versão 6): estudo piloto em adultos jovens brasileiros. Rev Bras Cien Mov. 2001;9(3):45-51.

31. Lopes VP, Magalhães $P$, Bragada J, Vasques C. Actigraph calibration in obese/overweight and type 2 diabetes mellitus middle-aged to old adult patients. J Physic Activ Healt. 2009;6(Suppl 1):S133-40.

32. Bussmann |B|, Horemans HLD, Hurkmans HLP. New frontiers in physical activity assessment with pattern recognition technology. International Conference on Ambulatory Monitoring of Physical Activity and Movement; Rotterdam; 2008.

33. Salvo D, Reis RS, Sarmiento OL, Pratt M. Overcoming the challenges of conducting physical activity and built environment research in Latin America: IPEN Latin America. Prev Med. 2014;69(Suppl 1):S86-92.

34. World Health Organization. Global status report on noncommunicable diseases 2010. Geneva: World Health Organization; 2011.

35. Ministério da Saúde. Vigitel Brasil 2014. Vigilância de fatores de risco e proteção para doenças crônicas por inquérito telefônico. Brasília: Ministério da Saúde; 2014.

36. Ministério da Saúde. Vigitel Brasil 2016. Vigilância de fatores de risco e proteção para doenças crônicas por inquérito telefônico. Brasília: Ministério da Saúde; 2016.

37. Tanner JM. Growth at adolescence. $2^{\text {nd }}$ ed. Oxford: Blackwell Scientific Publications; 1962.

38. Vitolo MR. Nutrição: da gestação ao envelhecimento. $2^{\mathrm{a}}$ ed. Rio de Janeiro: Rubio; 2008.

39. Sunaga FB. Sobre o uso e implicações do termo de assentimento para crianças em pesquisas biomédicas no Brasil [Dissertação]. Campinas: Faculdade de Ciências Médicas, Universidade Estadual de Campinas; 2015.

40. Associação Brasileira de Empresas de Pesquisa (ABEP). Critério padrão de classificação econômica Brasil. 2013. 